EESTI NSV TEADUSTE AKADEEMIA TOIMETISED. 29. KOIDE

FOOSIKA * MATEMAATIKA, 1980, NR. 2

ИЗВЕСТИЯ АКАДЕМИИ НАУК ЭСТОНСКОИ ССР. ТОМ 29 ФИЗИКА * МАТЕМАТИКА, 1980, № 2

удК 621.382 .3

Я. ААРИК, Я. БЕРГМАНН,

П. ЛЫУК, Я. ФРИДЕНТАЛ

\title{
ЗАВИСИМОСТЬ ХАРАКТЕРИСТИК АIGaAsSb-GaSb- ГЕТЕРОЛАЗЕРОВ ОТ СТЕПЕНИ СОГЛАСОВАНИЯ ПАРАМЕТРОВ РЕШЕТОК НА ГЕТЕРОГРАНИЦАХ
}

J. AARIK, J. BERGMANN, P. LOUK, J. FRIEDENTHAL, AIGaAsSb-GaSb HETEROLASERITE KARAKTERISTIKUTE SOLTUVUS VOREPARAMEETRI SOBITAMISEST HETEROSTRUKTUURIS

J. AARIK, J. BERGMANN, P. LOUK, J. FRIEDENTHAL. DEPENDENCE OF AIGaAsSb-GaSb DH LASER CHARACTERISTICS ON LATTICE MATCHING IN HETEROSTRUCTURE

\section{(Представил К. К. Ребане)}

В [ $\left.{ }^{1}\right]$ сообщалось о создании инжекционных лазеров с двусторонней гетероструктурой на основе четырехкомпонентных соединений AlGaAsSb, излучающих в диапазоне 1,5-1,78 мкм. Получение генерации при сравнительно невысоких плотностях порогового тока $j_{\text {пор }}=$ $=6,2 \kappa A / \mathrm{cm}^{2}$ при $300 \mathrm{~K}$ свидетельствует о достаточном совершенстве гетерограниц в использованных структурах. Однако более детальные данные о влиянии гетерограниц на характеристики этих лазеров отсутствуют. Поэтому нам представлялось интересным исследовать этот вопрос. Для изменения степени рассогласования параметров решеток варьировалось содержание мышьяка в широкозонных эмиттерах из $\mathrm{Al}_{x} \mathrm{Ga}_{1-x} \mathrm{As}_{y} \mathrm{Sb}_{1-y}$.

Двусторонние гетероструктуры были получены методом жидкостной эпитаксии. Выращивание осуществлялось при $570{ }^{\circ} \mathrm{C}$ в режиме принудительного охлаждения раствора-расплава со скоростью 0,3 град/мин. На подложку $p$-типа с ориентацией (100) наращивали эмиттер из $p-\mathrm{Al}_{x} \mathrm{Ga}_{1-x} \mathrm{As}_{y} \mathrm{Sb}_{1-y}$, активную область из $p$-GaSb и эмиттер из $n-\mathrm{Al}_{x} \mathrm{Ga}_{1-x} \mathrm{As}_{y} \mathrm{Sb}_{1-y}$. Толщина активной области $d$ исследованных лазеров составляла $0,8-2$ мкм.

Зависимость приведенной плотности порогового тока $j_{\text {пор }} / d$ от coдержания мышьяка в эмиттерах лазера показана на рис. 1 (кривая 1 ). Эта зависимость имеет минимум при $y=y_{\text {опт. }}$ В целях выяснения причин увеличения плотности порогового тока при отклонении от $y_{\text {опт }}$ исследовались вольтамперные характеристики лазерных диодов, квантовый выход люминесценции, внутренние оптические потери, а также параметры, определяющие оптическое усиление.

Оказалось, что плотности обратных и прямых токов этих диодов при малых смещениях $(\sim 0,1 B)$ сильно зависят от $y$ и имеют мини-

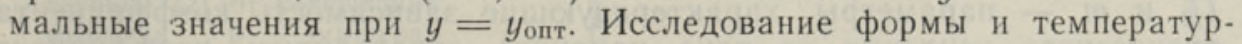
ной зависимости вольтамперных характеристик показало, что значительную роль в протекании тока играет, по-видимому, туннельно-реком-

8 ENSV TA Toimetised. $F^{*} M 21980$ 


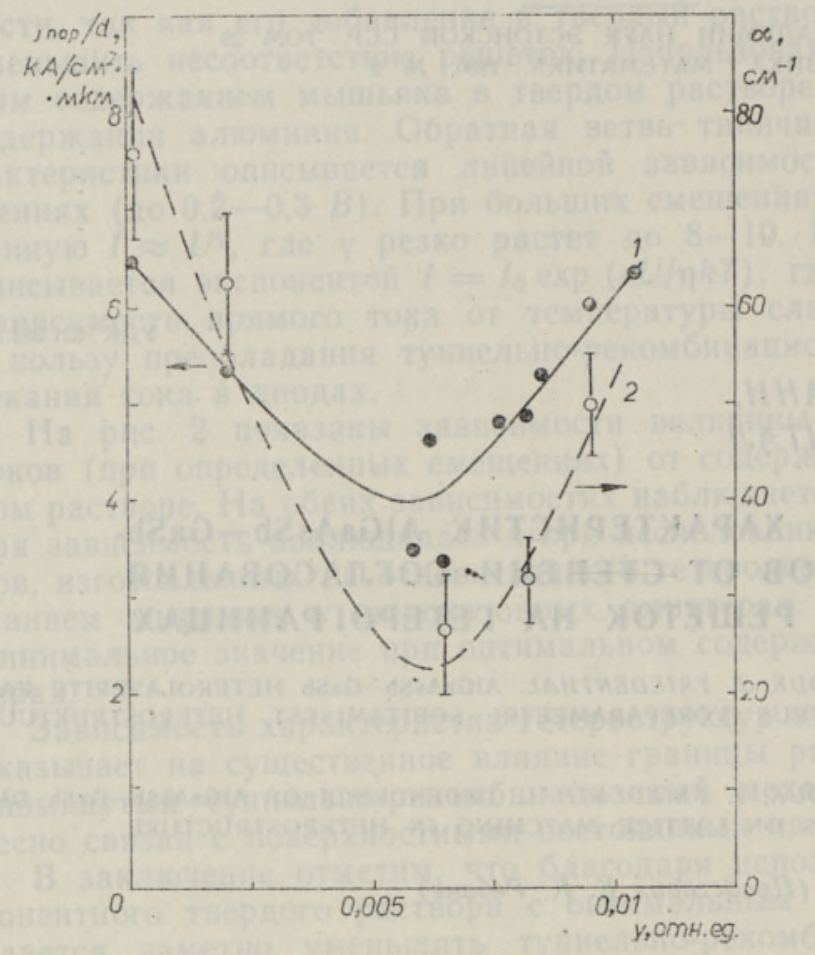

Рис. 1. Зависимость приведенной плотности порогового тока (1) и внутренних оптических потерь (2) от содержания мышьяк в эмиттерах

$\mathrm{Al}_{x} \mathrm{Ga}_{1-x} \mathrm{As}_{y} \mathrm{Sb}_{1-y}-\mathrm{GaSb}-$ лазеров $\quad(x=0,21 \pm 0,02)$.

бинационный механизм [2]. Резкая зависимость величины тока от $y$ свидетельствует об участии в последнем процессе локальных состояний, возникающих на гетерогранице из-за несоответствия параметров решеток. В пользу этого говорят и ваттамперные характеристики спонтанной электролюминесценции, показанные на рис. 2. Кривая 1 соответствует случаю $y=y_{\text {опт }}$, при котором

наблюдается максимальное значение квантового выхода люминесценции

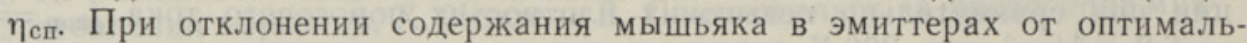

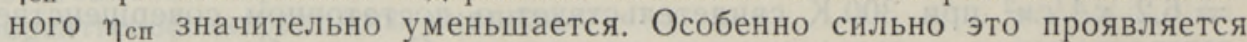
в области малых токов, где относительная доля туннельной составляющей больше. Более подробно характер зависимости $\eta_{\text {сп }}$ от $y$ изображен на рис. 3 (кривая 1 ).

C возрастанием прямого смещения преобладающей становится инжекционная составляющая тока. Об этом свидетельствует возрастание с током крутизны ваттамперных характеристик спонтанной электролюминесценции (рис. 2) и наблюдаемое при этом ослабление зависимости квантового выхода от $y$. Вблизи порога генерации зависимость квантового выхода люминесценции $\eta_{\text {сп }} \sim \beta$, где $\beta$ - «удельное» усиление, уже весьма слабая (рис. 3 , кривая 2).

В целях выяснения влияния несоответствия параметров решеток на свойства активного оптического волновода в условиях сильного возбуждения исследовались характеристики лазерных диодов в режиме генерации. По известным зависимостям плотности порогового тока $j_{\text {пор }}$ и внешней дифференциальной эффективности $\eta_{д}$ от внешних оптических потерь $\alpha_{p}\left[{ }^{3-5}\right]$ :

$$
j_{\text {пор }}=j_{0}+(1 / \beta)\left(\alpha+\alpha_{p}\right)^{m}
$$

H

$$
\eta_{\text {д }}=\eta_{\mathrm{c \tau}}\left(1+\alpha / \alpha_{p}\right)^{-1}
$$

( $j_{0}$ и $m$ - параметры, характеризующие зависимость коэффициента оптического усиления от тока накачки) определялись коэффициент внутренних оптических потерь $\alpha$, «удельное» усиление $\beta$ и внутренний 
Рис. 2. Зависимость интенсивности спонтанной электролюминесценции

$\mathrm{Al}_{x} \mathrm{Ga}_{1-x} \mathrm{As}_{y} \mathrm{Sb}_{1-y}-\mathrm{GaSb}-$ лазеров при $y=y_{\text {опт }}(1)$ и $y=0$ (2) от плотности тока. Оба лазера имели одинаковую геометрию - длина резонатора составляла 300 мкм, ширина 124 мкм, толщина активной области 1,4 мкм.

квантовый выход стимулированного излучения $\eta_{\text {ст }}$. При этом коэффициент внешних оптических потерь $\alpha_{p}=(1 / L) \ln (1 / R) \quad(L-$ длина резонатора и $R$ коэффициент отражения зеркал) варьировался путем постепенного укорачивания длины резонатора.

Оказалось, что в интервале приведенных плотностей тока от 5 до

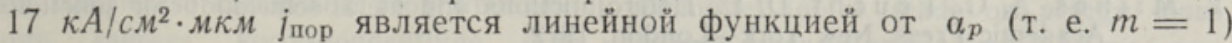
независимо от $y$. Установлено, что не только $\beta$, но и $\alpha$ зависит от $y$ и имеет минимум при $y=y_{\text {опт }}$ (рис. 1 , кривая 2). Следовательно, снижение порога генерации при уменьшении рассогласования параметров решеток на гетерограницах связано как с уменьшением внутренних оптических потерь, так и с небольшим увеличением «удельного» усиления. Интересно также отметить, что внутренний квантовый выход стимулированного излучения не зависит от $y$.

Итак, проведенные нами исследования показывают, что точным согласованием параметров решеток в гетероструктурах

$\mathrm{Al}_{x} \mathrm{Ga}_{1-x} \mathrm{As}_{y} \mathrm{Sb}_{1-y}$

- $\mathrm{GaSb}$ с небольшим содержанием $\mathrm{Al}(x \leqslant$ $\leqslant 0,23)$ можно заметно улучшить характеристики лазерных диодов как в режиме генерации, так и в спонтанном режиме. Особенно это касается

Рис. 3. Зависимость квантового выхода спонтанной люминесценции при $j / d=$ $=15 \mathrm{~A} / \mathrm{CM}^{2} \cdot$ мкм (I) и «удельного» усиления $\beta \sim \eta_{\text {си }}$ вблизи порога генерации (2) от содержания мышьяка в эмиттерах $\mathrm{Al}_{x} \mathrm{Ga}_{1-x} \mathrm{As}_{y} \mathrm{Sb}_{1-y}-\mathrm{GaSb}-$ лазеров.

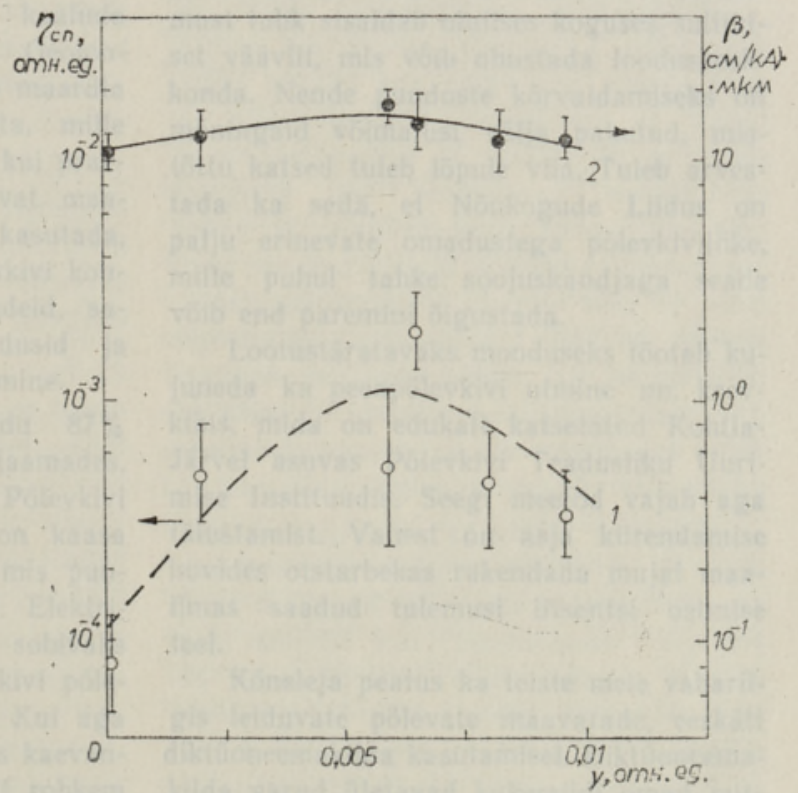


области малых плотностей тока. Так, например, диоды с оптимально подобранными составами эмиттеров могут превосходить по квантовой эффективности спонтанной люминесценции 'более чем на порядок диоды с трехкомпонентными эмиттерами $\left(\mathrm{Al}_{x} \mathrm{Ga}_{1-x} \mathrm{Sb}\right)$. В режиме генерации в этих же диодах эффект от оптимизации значительно слабее, по-видимому, вследствие насыщения связанных с гетерограницами центров рекомбинации и уменьшения доли туннельно-рекомбинационной составляющей тока.

Для достижения же непрерывного режима генерации выбор оптимального состава эмиттеров данных гетероструктур имеет, вероятно, принципиальное значение, поскольку он обеспечит не только минимальную плотность порогового тока, но и предупредит деградацию.

Авторы выражают благодарность К. К. Ребане за поддержку настоящей работы и П. Г. Елисееву за полезные замечания. Мы также благодарны Э. Карм, Х. Келле, Э. Куус и А. Вирро за помощь при подготовке и проведении эксперимента.

\section{Л ИТ Р Р А Т Р А}

1. Долгинов Л. М., Дружинина Л. В., Елисеев П. Г., Мильвидq к и й М. Г., С в е рдлов Б. Н., Квант. электроника, 3, № 2, 465-466 (1976).

2. Milnes, A. G., F e u cht, D. L., Heterojunctions and metal-semiconductor junctions, Academic Press, New York-London, 1972.

3. L a s her, G. J., IBM J. Res. Develop., 7, № 1, 58-61 (1963).

4. B i a r d, J. R., C a r r, W. N., Re ed, B. S., Trans. AIME, 230, 286-290 (1964).

5. Г риб ко в ский В. П., Теория поглощения и иепускания света в полупроводниках, Минск, «Наука и техника», 1975.

Институт физики

Академии наук Эстонской ССР
Поступила в редакцию 3/I 1980 